\title{
Rémy Leveau, Khadija Mohsen-Finan, Catherine Wihtol de Wenden (éds), L'Islam en France et en Allemagne. Identités et citoyennetés
}

Paris, La Documentation Française, 2001, 150 p. (annexes, encadrés)

Chantal Saint-Blancat

\section{OpenEdition}

Journals

Édition électronique

URL : http://journals.openedition.org/assr/621

DOI : 10.4000/assr.621

ISSN : $1777-5825$

Éditeur

Éditions de l'EHESS

Édition imprimée

Date de publication : 1 octobre 2002

Pagination : 63-126

ISBN : 2-222-96725-2

ISSN : 0335-5985

\section{Référence électronique}

Chantal Saint-Blancat, « Rémy Leveau, Khadija Mohsen-Finan, Catherine Wihtol de Wenden (éds), L'slam en France et en Allemagne. Identités et citoyennetés », Archives de sciences sociales des religions [En ligne], 120 | octobre - décembre 2002, document 120.26, mis en ligne le 24 octobre 2005, consulté le 21 septembre 2020. URL : http://journals.openedition.org/assr/621 ; DOI : https://doi.org/10.4000/ assr.621 
aussi souvent un rôle de médecin, d'agronome et généralement d'auxiliaire de l'administration, le curé est perçu au XVIII ${ }^{\mathrm{e}}$ siècle comme participant à un "service public d'utilité sociale ». L'appartenance des curés à la notabilité, ne doit pas faire oublier le mécontentement du bas-clergé dont les revendications viendront se mêler aux mouvements révolutionnaires.

Les chapitres rédigés par Michel Lagrée sur le $\mathrm{XIX}^{\mathrm{e}}$ siècle traitent de thèmes bien connus : apogée de la figure du «bon prêtre », déclassement social des curés, oppositions entre tendances gallicanes et ultramontanisme, développement des œuvres catholiques, anticléricalisme(s). Le grand intérêt de cette partie réside dans les perspectives comparatistes développées par l'auteur. Celui-ci met notamment en relation le joséphisme autrichien et le système concordataire français, tous deux visant à constituer des Églises nationales sous forte tutelle étatique. Il compare aussi les différentes formes de l'anticléricalisme latin (France, Italie, Espagne) ainsi que celles du régionalisme auxquelles des curés sont partie prenante. Enfin, il met en évidence un certain nombre de décalages temporels : retard irlandais dans l'application de la réforme tridentine et précocité de l'engagement du clergé allemand dans la voie du catholicisme social.

Après avoir montré le relatif apogée de la charge curiale dans l'entre-deux-guerres face à des tentatives de réformes encore bien timides, Luc Perrin met en évidence de façon très documentée les forces de déstabilisation de la paroisse et de son curé qui marquent ensuite l'Occident, dans un contexte de baisse de la pratique et d'assèchement des vocations. Nouvelles formes de division du travail religieux avec l'engagement croissant des laïcs et des diacres permanents dans la cure d'âme, redistribution du pouvoir au sein des structures diocésaines, paroisses d'élection, en sont les principales manifestations. L'A. relate aussi la remise en cause de l'idéal sacerdotal (célibat, exclusion de la vie politique et du monde du travail) par des groupes contestataires comme Échanges et Dialogue. Il finit par la description du reflux qui a lieu par la suite, semblant déboucher de façon logique selon lui sur un retour au modèle du XIXe, celui du curé d'Ars. À la position de L. Perrin qui a pour elle d'être en congruence avec la fixité romaine, on peut préférer la conclusion plus ouverte de N.L. (qui constitue d'ailleurs une excellente synthèse de l'ouvrage dans sa totalité): "Les expériences récentes qui voient des groupes, des réguliers, voire des femmes (...) en position de curé ne permettent pas de lire l'avenir de façon claire. Et si celui-ci devenait pluriel, conditionné par le choix des fidèles plutôt que par celui des autorités ecclésiastiques? » (p. 453).

L'ensemble des parties, toutes très denses, constitue un outil fort précieux pour tous ceux qui s'intéressent aux curés, à leur histoire et à leur devenir. Si l'on disposait déjà de nombreuses monographies (diocésaines et paroissiales) et biographies, mais aussi d'études s'étendant sur une période donnée, il manquait sur ce thème un travail d'une telle ampleur. Seul regret, l'absence d'une bibliographie générale.

Céline Béraud.

120.26

LEVEAU (Rémy), MOHSEN-FINAN (Khadija),

WIHTOL de WENDEN (Catherine), éds

L'Islam en France et en Allemagne. Identités et citoyennetés. Paris, La Documentation Française, 2001, 150 p. (annexes, encadrés).

Résultat d'un programme de recherche de l'Ifri (Institut français des relations internationales) sur la nouvelle identité européenne et la citoyenneté, cet ouvrage collectif analyse les changements en cours dans les relations entre les populations d'origine musulmane et les sociétés allemande et française : émergence de nouvelles formes de citoyenneté, renouvellement du lien complexe entre religion et politique, en particulier la question de l'institutionnalisation de l'islam en décalage avec un mode de fonctionnement et de régulation "par le bas », qu'imposent les stratégies plurielles et pragmatiques des acteurs.

L'introduction soulève trois facteurs déterminants dans la gestion de l'islam dans l'espace public : le poids du fait colonial, le processus historique de régulation politique du religieux dans les deux pays et la formation différenciée des élites dans le champ économique (Allemagne) et/ou associatif (France). On peut regretter que le premier élément et le troisième n'aient pas été davantage repris dans les différentes contributions, dont la précision des données et la reconstruction historique permettent d'éclairer le tournant décisif des relations actuelles entre l'islam et les deux États étudiés. Le lecteur risque ainsi de perdre certains fils conducteurs qui sous-tendent les grilles de lecture innovatrices de ce travail. Il s'agit, par exemple, de l'ina déquation du système politique, ancré sur des pratiques « christiano-centriques » (C. de Galembert, p. 87), d'une vision de l'islam collective et unitaire qui ralentit la prise de conscience d'une présence musulmane plurielle, aux identités instables et mouvantes (N. Tietze) ou de la déconstruction d'une "spécificité musulmane » 
qui relève davantage des transformations générales du champ religieux et politique (en particulier les nouvelles définitions des modes de citoyenneté).

Les deux premiers chapitres fournissent une réflexion sur l'évolution de la conception et de la pratique de la citoyenneté et montrent, malgré les divergences entre les deux sociétés (citoyenneté contre l'exclusion sociale en France et pour l'inclusion politique en Allemagne, R. Kastoryano, p. 32) la dissociation progressive entre citoyenneté et identité nationale, qu'illustre clairement le délicat problème de la double nationalité.

La reconstruction historique qu'opère R.L. au sujet de la sacralisation de l'appartenance religieuse comme seule stratégie légitime pour les maghrébins face à la gestion des conflits économiques et sociaux des années soixantedix, non gérables par le biais des médiations sociales habituelles, remet les pendules à l'heure et souligne le coût d'un choix identitaire "imposé », mal compris et superposé à une représentation conflictuelle de l'islam. L'analyse critique qu'il fait de la mouvance associative comme réponse palliative à un déficit d'intégration, aussi bien politique qu'économique (contrepoint de la réussite de l'ethnic business turc en Allemagne et du déficit de reconnaissance publique) trouve sa conclusion logique dans la possibilité pour l'islam européen de se construire à l'avenir autour d'une double identification : aux réalités locales de la diaspora et avec un Ailleurs d'origine où fidélité de la mémoire ne rime pas avec conflit. À long terme, cette recomposition ne saurait aboutir sans une réflexion théologique, une autonomie des diasporas par rapport aux sociétés d'origine sur des problèmes concrets, comme le statut de la femme ou le degré d'inclusion de la communauté, mais aussi une volonté de l'Europe d'établir des relations non conflictuelles avec les États musulmans du Sud et de l'Est méditerranéen.

Les deux chapitres suivants sont consacrés à la régulation étatique du culte musulman et démontrent la nécessité du passage d'une imposition par le haut à une auto-régulation des acteurs. F. Frégosi affronte les récentes tentatives de normalisation en France et éclaire judicieusement l'importance des réactions des organisations musulmanes face à l'obligation qui leur est imposée de ratifier un certain nombre de principes juiridiques de la République, notamment la possibilité de changer de religion ou la présence d'acteurs spirituels ou intellectuels au sein de la constituante qui choisira la représentation nationale de l'islam français. Son analyse éclaire le chemin parcouru et les risques de blocage. Elle est parfaitement complétée par l'approche comparative de C. de Galembert sur l'institutionnalisation de l'islam en France et en Allemagne. Vouloir à tout prix encadrer l'islam dans des normes de régulation pré-existantes, bref le «domestiquer », risque de se solder par un échec. Au lieu de prétendre à une instance unitaire de l'islam (surtout en France), le dispositif politique pourrait davantage prendre en compte un champ religieux en profonde transformation et reconnaître que les identités religieuses, en islam comme ailleurs, "se recomposent au gré des préférences, des ressources et des opportunités » (p. 92).

Cette dérégulation, remarquablement analysée ici au niveau des difficultés institutionnelles, se retrouve dans les deux derniers chapitres. Le texte de F. Frégosi sur les jeunes Turcs et leur tentative d'autonomie par rapport aux associations paternelles et celui de N. Tietze sur les jeunes maghrébins et turcs et leur recherche d'affirmation individuelle par le biais des formes de religiosité qui visent à rendre visible dans l'espace public une altérité qui souligne la réalité d'un traitement socio-économique inégalitaire, illustrent les recompositions en cours au niveau générationnel mais aussi en terme de contenu identitaire.

La conclusion de C.W.deW. ouvre des perspectives de réflexion et de synthèse sur le dynamisme et le questionnement que l'islam fournit à une identité européenne en mal de créativité et d'imagination. Elle s'inscrit comme l'ensemble de cet ouvrage dans une perspective "post-nationale » et suggère de repenser les catégories du territoire, de l'allégeance et de la mobilité sociale. D'utiles encadrés, ponctuels et originaux complètent ce travail.

Chantal Saint-Blancat.

MAISONNEUVE (Roland).

Dieu inconnu, Dieu trinité. Anthologie Comment les mystiques chrétiens « voient » Dieu un et trine. Paris, Cerf, 2002, 212 p. (bibliogr., index).

Dans son précédent ouvrage (Les mystiques chrétiens et leurs visions de Dieu un et trine, Paris, Cerf, 2000 - cf. Arch. 114, 2001, pp. 520), R.M. s'interrogeait sur la nature de la vision et le concept d'image dans la relation des 